\title{
CINCO VARIANTES GUANACASTECAS DEL TIPO 510 \\ DE AARNE Y THOMPSON \\ ("LA CENICIENTA" $Y$ "PIEL DE ASNO")
}

\author{
Juan Santiago Quirós Rodríguez \\ Centro Universitario de Guanacaste
}

\begin{abstract}
This article includes five versions from the Guanacaste area of Aarne and Thompson's Type 510 , better known in Spanish-speaking countries as "La Cenicienta" and "Piel de Asno".

Each version is analyzed according to its fundamental features of type, motives, submotives, and characters; and a comparison with the analysis made by Aarne and Thompson is established.

Some biographical data about the five story tellers is included, as well as a brief discussion of their narrative styles.
\end{abstract}

\section{INTRODUCCION:}

La mayor parte de las narraciones folclóricas costarricenses pertenece a la tradición cuentística popular que, nacida en tiempos inmemoriables, se extendió por los países euroasiáticos y de ellos, a América.

Tal difusión explica las semejanzas que existen entre narraciones rusas, danesas, españolas -para nombrar sólo tres-y las hispanoamericanas, en las que difieren, a veces, un motivo, un rasgo, quizás uno o dos personajes, pero manteniéndose apenas invariable el argumento.

Estas similitudes podrán apreciarse claramente en las cinco versiones que se transcribirán, tomadas en Guanacaste, en una investigación realizada con alumnos de Humanidades del año 85.

1. Método de recolección de cuentos y datos sobre los informantes:

1.1. A cada alumno se le explicó lo que es un cuento popular, sus rasgos y características, y se le pidió que tratara de recoger uno en su pueblo, preferentemente de personas mayores; que antes de grabarlo, lo narrara a todo el grupo para tener seguridad de que pertenece a la tradición popular.
Una vez hecha esta constatación, el alumno procedió a grabarlo, en la voz del narrador, y a aplicarle a éste la llamada "encuesta fólclórica" (Pinon, 1965:21), con el fin de fijar las características del momento en que suele contarlo. Posteriormente, tomó sus datos biográficos. Esto último se solicitó, porque actualmente se considera al narrador como parte esencial del estudio del cuento. No se ve en él a un simple "recitador" sino a un coautor que con su versión, disminuida o aumentada en relación con otras, ha recreado el cuento y lo ha enriquecido con variantes novedosas, muy ligadas a su idiosincrasia y a particularidades de la región en que vive.

1.2. Enriqueta Rosales Vallejos, entrevistada por el alumno Nésmer Antonio Ruiz Rosales. Nació en San Francisco, caserío del distrito de 27 de abril, Santa Cruz, el 3 de marzo de 1924. Casó en 1948 con Carlos Manuel Ruiz Contreras, con quien tuvo 8 hijos.

Aprendió el cuento "La Cenicienta" de su abuela María Ruiz Molina, cuando tenía 12 años de edad.

Actualmente ya no cuenta ningún cuento; pues -según sus palabras- "la niñez se dedica a oír radio y a ver televisión, y no le gusta sentarse a escuchar un cuento de éstos". 
1.3. Juana Pastora Gutiérrez Moraga, entrevistada por Angela Mayela Cascante Gutiérrez, nació en San Juan de Santa Cruz, el 29 de marzo de 1929. Casó con Enrique Cascante en 1953. Tuvo 9 hijos. Estudió hasta segundo grado.

Aprendió el cuento "La María Cenicienta" cuando tenía 5 años, de su maestra Gregoria Hernández.

Casi nunca lo cuenta. Lo hacía para que sus hijos, pequeños, se durmieran.

1.4. Raimunda Gutiérrez Gutiérrez, entrevistada por Magda Yesenia Alvarez Moraga. Nació el 15 de marzo de 1925, en Santa Ana de Nicoya. Se casó en 1945 con Francisco Moraga Cascante. Tuvo 4 hijos.

El cuento "María Cenicienta" lo oyó a su tío Antonio Gutiérrez, cuando ella tenía 12 años de edad.

Ya no cuenta cuentos; pues los jóvenes tienen otras distracciones, como el cine, la discotheque, la radio y la televisión, y no tienen interés en oírlos.

1.5. Noé Bustos Rodríguez, entrevistado por Sandra Virginia Gutiérrez Ruiz, nació en Tempate, Santa Cruz, el 11 de marzo de 1910. Tiene 4 hijos. Aprendió el cuento "María cara'e yegua" de su abuela, cuando contaba con 11 años de edad.

Actualmente no cuenta cuentos, ya que no tienen a quien hacerlo.

1.6. Marina Raffo Cárdenas, entrevistada por Magda Cecilia Durán Chacón, nació en Nicoya, el 28 de setiembre de 1906. Tuvo 5 hijos. Fue maestra en Quirimán, Guastomatal, Curime, Matina, Matambú y Santa Cruz.

El cuento "Primero a Dios, después a la sal y después a usted", lo aprendió de su director Higinio Vega, cuando ella tenía 7 años.

Ya no los cuenta.

\section{METODOLOGIA:}

El método que se aplica en el análisis y transcripción de estos cuentos, es el histórico-geográfico-finés (Dorson, 1972: 7 y ss.), cuyos postulados más importantes son los siguientes:

1. Un cuento popular es producto de un tiempo y de un lugar determinados, y de un acto consciente de invención (origen monogenético para cada cuento).

2. De su lugar de origen, se difundió en ondas cada vez mayores, siguiendo las rutas existentes de viajeros, mercaderes y conquistadores.
3. Cruzó con facilidad fronteras lingüísticas y culturales; siempre de un pueblo civilizado a otro que lo era menos.

4. De él se halla siempre gran cantidad de versiones.

5. Cada una de éstas debe analizarse en su argumento básico y en sus rasgos o componentes esenciales, con el fin de establecer, por medio de mapas, las rutas y zonas de distribución y asentamiento.

Asimismo, se hace un estudio comparativo de los motivos presentados por Thompson (Thompson, 1960: 175 y s.s.) junto con los que cada cuentista guanacasteco presenta en su versión.

Es conveniente incluir aquí, el sentido que Thompson les da a "tipos" y "motivos".

El "tipo" es un cuento tradicional con existencia independiente, que forma unidad en sí mismo y, por lo tanto, no necesita de otros cuentos para tener significado. Puede poseer uno o varios.

El "motivo" es el elemento más pequeño en un cuento, y tiene la particularidad de persistir en la tradición.

Puede subdividirse en tres clases:

a. personajes ("actors"), como dioses, hadas, ogros, animales y seres humanos arquetípicos: el hijo más joven, la cruel madrastra, el hermano tonto, etc.

b. ítemes en el desarrollo de la acción: objetos mágicos, trajes inusuales, creencias extrañas.

c. Incidentes singulares - que engloba la gran mayoría de motivos- (ibid 415 y 416), es decir, acontecimientos, acciones o sucesos que constituyen la esencia misma del cuento.

\section{RESUMEN DE LAS VERSIONES CON SUS MOTIVOS.}

3.1 Motivos de la versión de Thompson, Tipo 510. (Thompson, 1964: 177 y s.s.).

I. La heroína perseguida:

a. La madrastra y hermanastras abusan de la heroína; por esta razón, vive en la chimenea o en las cenizas y viste ropas burdas.

b. Huye de su padre, disfrazándose; pues él quiere casarse con ella.

c. Su padre la expulsa, como un castigo a su actitud. 
ch. Va a ser asesinada por un criado.

II. La ayuda mágica:

La recibe de:

a. Su madre muerta

b. Un árbol en la tumba de su madre

c. Un ser sobrenatural

ch. Pajarillos

d. Una cabra, una oveja o una vaca.

e. Al ser sacrificada la cabra (la oveja o la vaca), de sus entrañas aparece un árbol mágico.

III. Encuentro con el príncipe:

a. Lo conoce en la iglesia o en un baile. A éste llega con ropas hermosísimas; el príncipe trata en vano, de detenerla.

b. Ella deja entrever el abuso de que es objeto como sirvienta.

c. A ella la ven en ropas hermosísimas en un cuarto o en la iglesia.

IV. Prueba de identidad:

a. Descubren su identidad mediante una zapatiIla.

b. Podría ser mediante un anillo que deja caer en la bebida del príncipe o en el horneado que le prepara.

c. Ella es la única capaz de arrancar la manzana de oro que desea el caballero.

V. Matrimonio con el príncipe:

(No presenta submotivos).

VI. Prueba de la sal:

Al padre se le alimenta sin sal, por lo que llega a conocer el valor de sus palabras.

3.2. Motivos de "La Cenicienta", de Enriqueta Rosales Vallejos.

I. Heroína maltratada.

a. Madrastra cruel.

b. La heroína es maltratada con trabajos serviles (lavar tripas de cerdo en el río).

II. Ayuda mágica. a. Se la proporciona una señora.

b. Debe hacer algo para obtenerla.

c. Recibe una varita mágica y un lucero en la frente.

III. Encuentro con el príncipe.

a. La heroína va a la iglesia, dos veces, con un hermoso vestido.

b. El príncipe se enamora de ella

c. Con cera en la puerta, él obtiene el zapato de ella.

IV. Prueba de identidad.

a. Ella es descubierta por medio de la zapatilla.

V. Matrimonio con el príncipe.

a. La madrastra cambia a María Cenicienta por una de sus hijas.

b. Por la plaza, una lora descubre el engaño.

VI. Prueba de la sal

No aparece ninguno de estos submotivos.

3.3 Motivos de "La María Cenicienta", de Juana Pastora Gutiérrez Moraga.

I. La heroína maltratada.

a. por la mamá, que tiene 2 hijas más.

b. Viste con ropas viejas.

II. La ayuda mágica.

a. Se la otorga Dios, como premio a sus ruegos, mediante una varita mágica.

III. Encuentro con el príncipe.

a. Asiste a tres bailes con ropas hermosísimas, y baila sólo con el príncipe.

b. No debe revelar cómo ha conseguido los vestidos.

IV. Prueba de identidad.

a. El príncipe tiró una saliva.

b. En ella se quedó pegado un zapato de María Cenicienta.

c. Mediante ese zapato, el príncipe la descubre. 
V. Matrimonio con el príncipe.

(No aparece ningún submotivo).

VI. Prueba de la sal.

(No aparece ningún submotivo).

3.4 Motivos de "María Cenicienta". Versión de Raimunda Gutiérrez Gutiérrez.

I. La heroína maltratada.

a. Por una madrastra y dos hermanastras, quienes la hicieron su sirvienta y la pusieron a dormir en la ceniza.

II. La ayuda mágica.

a. Un viejito, en el río, cuando ella va a lavar tripas, la regala un lucero brillante.

b. Una hada le da una varita mágica; con la condición de abandonar el baile a las doce de la noche.

III. Encuentro con el príncipe.

a. Va a un baile (una sola vez), elegantemente vestida, y el príncipe baila con ella.

IV. Prueba de identidad.

a. Al salir del baile, deja perdida una zapatilla.

b. Mediante ésta, el príncipe la reconoce.

V. Matrimonio con el príncipe.

a. La madrastra, mediante un engaño, introduce en la carroza real a una de sus hijas.

b. El rey se casa con María Cenicienta y, por envidiosas, sus hermanastras se quedan viviendo como siempre.

VI. Prueba de la sal.

(No aparece ningún submotivo).

3.5. Motivos de "María cara'e yegua" de Noé Bustos Rodríguez.

1. La heroína maltratada.
La muchacha huye de su padre, que se ha enamorado de ella, y vive, cuidando gallinas, bajo una piel de caballo.

II. La ayuda mágica.

a. Se la brinda el caballo más achacoso del corral: le habla, le da su piel y, muerto, la lleva al baile.

III. Encuentro con el príncipe.

a. Lo conoce en el baile, vestida con ropas hermosísimas. Va dos veces.

b. El príncipe le coloca un anillo en el dedo.

IV. Prueba de identidad.

a. La descubre mediante el anillo.

V. Matrimonio con el príncipe.

a. Se casa con el príncipe.

VI. Prueba de la sal.

(No aparece).

3.6. Motivos de "Primero a Dios, después a la sal y después a usted", de Marina Raffo Cárdenas.

I. La heroína maltratada.

a. Un rico hacendado manda a matar a su única hija con los criados; porque ella afirma que primero quiere a Dios; después a la sal $y$, por último, a él.

b. Ellos la dejan, por lástima, en media montaña.

c. Ella se cubre con una piel de mono.

ch. Un muchacho se la lleva para la casa, y la mete en una especie de perrera.

II. La ayuda mágica.

(No aparece ningún submotivo).

III. Encuentro con el príncipe.

a. El muchacho, que no es príncipe, hace una fiesta para encontrar esposa. 
b. La joven va al baile vestida con hermosas ropas que halló en un ropero.

c. El muchacho baila sólo con ella, y le da un anillo.

ch. Apenas puede, ella huye del lugar.

IV. Prueba de identidad.

a. La muchacha echa el anillo en un chocolate que prepara para el joven.

b. El la descubre por medio de ese anillo.

V. Matrimonio con el príncipe.

a. Con gran lujo, se prepara la boda.

b. Ella solicita que inviten a su padre.

VI. Prueba de la sal.

a. Al padre, ella le sirve la comida sin sal.

b. Cuando ve que no la come, ella se identifica como su hija.

3.7. Comparación de motivos entre la versión de Thompson según los apartados 3.1 (p. 4) y las cinco versiones guanacastecas.

Las cinco versiones guanacastecas pertenecen al Tipo 510 de Aarne y Thompson, identificado con "La Cenicienta" y sus variantes. Incluso, presentan las mismas sub-divisiones.

a. - Tipo $510 \mathrm{~A}$, es el cuento de "La Cenicienta", propiamente dicho. A él pertenecen los tres primeros:

"La Cenicienta", versión de Enriqueta Rosales Vallejos.

"La María Cenicienta", narrado por Juana Pastora Gutiérrez Moraga, y

"María Cenicienta", de Raimunda Gutiérrez Gutiérrez.

b. - Tipo $510 \mathrm{~B}$, se identifica con el conocido en los países de habla hispana como "Piel de Asno". Se identifican con este Tipo, los cuentos.

"María cara'e yegua", de Noé Bustos Rodríguez, y

"Primero a Dios, después a la sal y después a usted”, de Marina Ruffo Cárdenas.
Las semejanzas de motivos, anotadas en 0 (Introducción), se ejemplifican así:

I. La heroína perseguida:

a. - En 3.2 y 3.4 , por una madrastra.

En 3.3 es la propia madre la que la ultraja.

En 3.5 y 3.6 es el padre, de quien ella huye.

b. - $\quad 3.4$ es la única versión en que la protagonista vive en la ceniza.

3.3 dice que viste ropas viejas.

En 3.2 y 3.4 lava tripas.

Las demás no lo mencionan.

c. - En 3.5, ella huye de su padre, porque él se enamora de ella, y cuidará gallinas.

ch. - En 3.6, el padre manda a matarla con ayuda de sus criados, por decirle ella que lo quiere después de Dios y de la sal, y vivirá en una especie de perrera.

II. La ayuda mágica:

En las cinco versiones guanacastecas, no aparecen los submotivos a), b), ch), ni e).

Se presentan:

c. - Un ser sobrenatural. (Cfr. "Estrellita de Oro", versión de Fernán Caballero). En 3.2 es una señora, sin especificar nada más. Lo hace mediante una varita mágica.

En 3.3 es Dios, quien también le da una varita.

En 3.4, hay dos personajes: un viejito y una hada. Esta le da una varita.

d. - Una cabra, una oveja o una vaca.

En 3.5, la ayuda la brinda un caballo que, por sus cualıdades, es sobrenatural: habla y, muerto, acompaña a la heroína al baile.

3.6 no presenta ningún tipo de ayuda mágica.

III. Encuentro con el príncipe

a. - En tres de las versiones, ella conoce al príncipe en un baile. Sólo en la 3.2, lo conoce en la iglesia y, en la 3.6, cuando ella está subida en un árbol; aunque 

posteriormente, él se enamora de ella en un baile.
b. - Los submotivos b) y c) no aparecen en las cinco versiones antes dichas.

IV. Prueba de identidad:

a. $\quad$ - Las versiones $3.2,3.3$ y 3.4 utilizan el submotivo de la zapatilla.

b. $\quad-\quad 3.5$ y 3.6 recurren al del anillo.

El submotivo c) no se presenta en estas versiones.

V. Matrimonio con el príncipe.

La versión de Thompson no desarrolla ningún submotivo en este apartado. Simplemente, anota que hubo matrimonio con el príncipe. En la 3.3., el príncipe se casará con ella. 3.5. dice que se casa.

Las versiones guanacastecas 3.2 , y 3.4 presentan la variante de que una de las hermanastras se hace pasar por la heroína.

(Cfr. "La negra y la rubia" de Carmen Lyra).

En 3.6, la boda se prepara y, como invitado especial, figura el padre de la joven.

VI. Prueba de la sal.

Este motivo no aparece en las versiones analizadas; excepto en la 3.6. En ella, la joven le sirve al padre comida sin sal, para que él aprecie el valor de la respuesta dada por ella: "Primero (quiero) a Dios; después a la sal y después, a usted".

\section{Transcripción de los cinco cuentos:}

4.1. La siguiente transcripción tiene como finalidad reproducir, de la manera más fidedigna posible, la pronunciación empleada por los narradores.

Para ello, ha sido necesario utilizar signos diacríticos y explicaciones entre paréntesis. Cuando por diversas causas la transcripción se desvirtúa, o no se logra una reproducción fiel de lo grabado, habrá una indicación expresa que así lo consigue.

4.1.1 Signos más empleados en la transcripción:

[h] Representa la aspiración que en el dialecto de Guanacaste, sufre la s posnuclear. Indican una pausa.
Entonación intensiva que recibe la palabra o la frase bajo la cual se ha trazado.

\subsubsection{La Cenicienta (1)}

(Narrado por Enriqueta Rosales Vallejos).

(Narrado muy despacio)

Había una veez una señora que tenía dos hijas, y tenía una mota, que era hue...; ella la estaba criando, una húerfana; pero esa güila la tenía ella, esa muchacha ahí -de empleada, mejor dicho, $-y$ ella se iba los domingos a ver misa y a pasear; salía con lah hijah.

Un domingo, mató un chancho.

-Andáte a lavar esah tripah. Si voh me traéh una menoh, te apaleo -le dice-. (Dicho más rápido).

Se fue la María Ceniza, y se le suelta una tripa. $Y$ va esa María Ceniiiza detrás de esa tripa (muy rápido): aquí la agarro; aquí no la agarro.

Allá, abajo el río, estaba una señora lavando.

-Buenoh díah, señora -le dice-.

-Buenos días, buena hija. ¿De qué llora? -le dice-

-Ay, señora, que se me soltó una tripa -le dice- y si no la llevo, mi mamá me apalea-.

-No llore, -le dice-, aquí le tengo yo la tripa; pero hágame un favor -le dice-. Váyase por ese caminito y alláa está una casita; ahí está un niño en una hamaca $y$, si está despierto, -le dice- lo duerme y, si está dormido, ahí lo deja. Y en la mesa hay una palangana de agua $y$, cuando cantel burro, mete la cara y, cuando cantel gallo, la saca.

Hallól niño llorando, se puso y lo durmió (rápido) y al rato ya canta el...el burro. Mete la cara en la palangana de agua, y ahí cantó el gallo y la sacó y sale con un gran lucero en la frente que le iluminaba; y esa muchacha asustada, vino y se envolvió la cabeza.

-Y ahí, detráh de la puerta, -le dice- (rápido) hay una varita; usté la agarra y todo lo que usté le pida a esa varita, usté, ella se lo da-.

Se fue ella con la varita y con la cabeza envuelta. Ya... esté..., cuando llegó...ya...esté...la vieja llegó, verdá.

Ese otro domingo, vuelven a irse. Entonces, dice la María, la María Ceniza:

- Ahora voy a probar a ver si es questa varita me va (rápido) a dar todo.

$Y$ ya le dice:

-Varita, varita, por la virtú que Dios te dio 
(rapidísimo) -le dice-dame un buen vestido - le dice- y hacéme un poco de rohquillah-. Que le hab ían dicho que hiciera.

$Y$ ya llega un poco de mujereh y dicen a hacer esah rohquillah; ya la alistaron y llega un carro y se monta esa María Ceniza y se va a oír misa, y ya llega el príncipe y se queda viendo a esa muchacha, enamorao de la muchacha; pero hasta ahí, no sabía ni de dónde era, ni quién era, ni nada.

Bueno, ese otro domingo, lo mihmo. $Y$ ya le dice un día la vieja:

-Y ¿quéh lo que tenéh, María Ceniza? -

- Ay, que me duele la cabeza -le dice-.

-Mentira -le dice-, trae para ver quéh lo que tenés (rápido y muy enojada).

$Y$ ya le soltó la cabeza y le va viendo el gran lucero.

- ¿Y eso, cómo lo, lo tenéh, eso? -le dice-.

$Y$ ya la muchacha tuvo que contarle cómo era.

Pues ese otro domingo, ya se manda a la hija a lavar lah tripah. Ya la muchacha afloja lah tripah y ahí va bajo el río.

- Aquí la agarro, aquí no la agarro (rápido).

Y ya llega donde estaba la señora, y ya...llorando.

- ¿De qué llorás - le dice la señora.

-Ay, señora, -le dice- que se me soltó una tripa -le dice- ...y si no la llevo, mi mamá me apalea.

-No llore -le dice- aquí está la tripa.

Bueno, ya se la dio...

-Ah no, -le dice- pero usté se va por ese caminito, y si el niño está dormido, usté lo duerme -le dice- lo des...si ehtá llorando, lo duerme y si ehtá dispiert...ji, ji, ji (risa como nerviosa, quizá por el error).

Ya se fue y el niño estaba dormido y entonces vino y le pega unah nalgadah, y ya... esté... lo durmió y al rato, cantó el, el gallo. Metió la cara, y ahí canta el burro. Sale con la badaja en la frente pegada, y ya se fue con la cabeza envuelta, y llega - dice- y la vieja alegre se fue y le desenvolvió la cabeza y sale con la badaja.

Bueno, y ese otro domingo, la misma cosa; y ya el príncipe había puesto un poco de cerapé en la puerta, a ver... que ahí tenía que pegarse la zapatilla (muy rápido), verdá. Ya cuando salió la muchacha, se le pegó la zapatilla ahí, y ya corre el príncipe y agarra esa zapatilla. $Y$ ya se va de casa en casa, a ver quién le quedaba la zapatilla. Bueno, ya sólo esa casa le faltaba, y ya llega.

-Señora, señora, ¿usté tiene hijas?

-Sí -le dice - tengo dos.
-Este, tráigame una de ellah -le dice.

Ya llamó la mayor... que se midiera la zapatilla.

No le quedó.

Llamó la menor...

Tampoco.

- ¿Y no tiene otra? -le dice-

-Sí (muy tenue; apenas si se oye)... iNo! -le dice - ino!

$-i$ No? Pero yo veo una en la cocina -le dice el príncipe-.

-No... ésa no. Eso no sale -le dice- sólo ahí metida vive (con voz despectiva).

- iTráigala! Palabra de rey.

Ya llegó... Ilegó la muchacha y se le metió la zapatilla. $Y$ ya le dice:

-Bueno, tal día vengo yo a ver. Me tiene lista la muchacha -le dice-.

Y ya llegó el carro a ver la muchacha, verdá. Y tenía una de lah hijah lihtah ella. Se fueron y, onde iban pasando frente del de una casa, le dice una lora:

- Jajai, badaja de burro en plaza; lucero brillante en casa.

Le dice el príncipe:

- ¿Cómo? , lorita.

- Badaja de burro en plaza; lucero brillante en casa -le dice.

-Usté me está engañando, señora, -le dice(rápido).

-No,-le dice-, ipor qué?

- iAh! -le dice - oiga lo que dice la lora. ce-

- ¿Quién le hace caso a loh animaleh? -le di-

-No, no, no, no -le dice-, traiga la muchacha que está en la cocina.

$Y$ ya la llamaron...No, ya se van para atráh, verdá, y en lo que llegan, van viendo de largo iluminar la casa. do?

- ¿Se fija -le dice- que usté me está engañan-

Pueh ya entonces apiaron la hija de ella del carro, y llevaron la muchacha María Ceniza en el carro, y se fueron a casarse con el príncipe.

Y colorín colorado. Este cuento ha terminado.

\subsubsection{La María Cenicienta (2)}

(Narrado por Juana Pastora Gutiérrez Moraga).

(Narrado muy despacio). 
Había una vez, una señora tenía tres hijah; pero a una le Ilamaban sólo la María Cenicienta. Las otras no...no tenían nombre. Entonceh, ella le dice:

- ¿Por qué voh no te mudás y las demás sí...se mudan?

Entonces dice ella:

-Pero, icómo me voy a mudar si yo no tengo ropa? Usté sólo a lah demáh leh compra, y a mí, a mí no me compra.

- Bueno, te vas a quedar - dice-para toda la vida, María Cenicienta; porque nunca te arihquiáh; todo el tiempo andáh sucia.

- iQué importa! Algún día llegará la suerte a mi casa.

Allá, un día,, dicidieron a irse a pasear. Entonce se quedó la María Cenicienta en la casa, y ellah doh se fueron y había baile. Y ellah doh bailando, y la María Cenicienta en la casa. Entonces, viene y le dice:

-Dios mío, reparáme cómo...cómo poder yo no ser la María Cenicienta.

Entonces vino y le reparó una varita, y le dice: -A esta varita, le pide la virtú que usté necesita. Entonces, le dice:

-Varita, varita, por la virtú que tú me ha dado, quiero que me deh el vestido más lindo que tengás, para ir... para ir yo al baile.

Entonces, viene la María Cenicienta, se quitó el vestido que tenía, se mudó y se puso los zapatos y entró al baile. Cuando ella llegó allá, lah hermanah se quedaron admiradas en ver esa mujer tan elegante que llegó.

Cuando ya se terminó el baile, se fueron para la casa. Ya la María Cenicienta estaba en la casa. Y entonces, le dice:

- ¿Te fijáh? -le dice- por...porque vos sos lerda y sucia, no tenés cómo mudarte, no fuistes al baile. Bieras visto. $Y$ dicen que la que llegue mejor vestida mañana, se casa con el príncipe.

-Ah, (cambia de voz para denotar indiferencia) qué importa -le dice- si de por sí, yo soy así, sucia. ¿Qué voy hacer, si soy María Cenicienta? No tengo nada que que hacer.

Entonces, ese otro día se volvieron a alistar las muchachas. Se fueron para para el baile otra vez. Y entonces, le dice:

-Te quedás -le dice- y son al decir los tres bailes, la que vaya mejor vestida, se casa con el príncipe.

Se fueron lah muchachah con la mamá. Llegaron al baile y las recibieron. Al rato, llegó la María Cenicienta. Pero...antes de irse, le dice:
- Varita, varita, por la virtú que tú me ha dado, dame el vehtido más elegante hoy y otro par de zapatoh...para yo poder ir al baile.

Entonceh se fue, se despidió de la varita y se mudó y se fue. Cuando llegó al baile, estaba comenzando. Entonces de una vez, se dirigió el príncipe a la, a la María Cenicienta, y estuvo bailando con ella. $Y$ aquella otras enchiladas, porque no las sacaban a bailar. Según ellas, andaban más bien mudadah. $Y$ entonces, se volvió a ir para la casa. Ya cuando llegaron lah otrah, estaba bien sucia. Ya le dicen:

-Vieras que, qué bonito que estuvo. $\mathrm{Y}$ el príncipe bailaba con una muchacha pero muy bonita. Pero mañana nosotras noh vamoh a poner el mejor vestido, porque hoy es...dos veces - dice $-y$ al decir las treh...el que se case, el que llegue pri...más bien vestida, se casa el príncipe.

- Bueno -le dice- qué importa - dice-y van a ver que ésa voy a ser yo.

- ¿Qué vas a ser vos? ¿Cómo te vas a mudar si vos no tenés ni. segundo vestido?

-Bueno, van a ver...que ésa...ésa, la esposa del príncipe voy a ser yo -le dice-.

Ese otro día, se volvieron a ir al baile. Entonces...el... llegaron. Dice el príncipe:

- Hoy, yo sigo a esta, a esta muchacha, a ver a dónde llegue y, adónde llegue, yo me, voy a...yo le...voy...yo me voy a escupir el zapato, y ahí tiene que quedar el zapato pegado, y yo voy a ir a preguntar a todas esas partes, a ver dónde están esas tres muchachas para que me...para que me, me sigan...me sigan a la persona.

Al decir los tres días, llegaron a...al baile otra vez, y llegó y le dice a la...la varita:

- Varita, varita -le dice- éste es el último día -dice-dame el mejor vestido y el mejor calzado; porque yo quiero ser la esposa del príncipe.

-Ehtá bien, se lo voy a dar -dice-pero eso sí, no diga cómo usté le reparó esa suerte; invente algo -le dice - para que diga que...como fue que le reparó.

Llegó y bailó, y dieron...hicieron un banquete ahí. La muchacha tenía que venirse antes que las demás...este...se salieran. Cuando ella salió, dicen que le echó una, una saliva al zapato y se quedó pegado. Entonces, se fue para la casa con un zapato. Al rarito, llegan ellas.

(Cambio de voz para imitar la de las hermanas). -Ay, -dicen- ahora sí - dice- vamos a ver -dice-quién es la que se va a casar con el príncipe; porque a él le quedó el zapato, y él va a venir en casa en casa, al preguntar, a ver quién fue. 
-Ojalá que sea yo - decía la mayor-

Dicía la otra:

- No, tiene que ser yo.

$-Y$, ¿si soy yo? -le decía la menor-

- ¿Vos? ¿Qué vas...cómo vas a crer - dice-que vos, que vos vas a llegar a esto, a casarte con el príncipe?

La cosa es que al momento...esto....legó el príncipe, y llegó primero ahí, donde esa gente, y le dice:

-Buenas tardes.

-Buenas tardes -le dicen-Pase adelante. ¿Qué se le ofrece?

-Vea - dice- ¿a cuál de ustedes se le quedó el zapato?

Entonces, le dice:

- A mí -le dice la mayor-seguro fue a mí.

- Medítelo, muchacha -le dice la mamá-

Y ella midiéndoselo.

-Es que no me queda. dedoh.

-Pues, muchacha, trozáte la punta de los

$Y$ viene la muchacha y se trueza la punta de los dedos, para para que le quedara el zapato. $Y$ no le quedó.

Entonces, la otra la...le dice:

-A mí sí me queda -le dice- yo voy a ser la ehposa del príncipe.

Entonces, le dice:

-Mida... póngaselo; si en eso ando.

Ya se lo pone, y la muchacha batallando y no le quedaba.

Entonces, le dice la mamá:

-Muchacha, trozáte el talón

Entonces, le...se trozó el talón.

Le dice:

- iY no tiene otra?

-Sí hay otra; pero esa muchacha nunca sale. ¿No ve que sólo sucia vive? Hasta que da vergüenza que la vean.

-Pero, póngaselo. Diay, tal vez.

-Vení, María Cenicienta, vení; ponéte este zapato.

Y ya llega a ponérselo y le quedó... le entró al pie.

Entonces, le dice:

- Ah, pues con usted me... con usted me caso -dice-

- Ay, no -dice- ¿Cómo va a casarse con esa mujer sucia? - dice-Mejor cásese con una de nosotras.

Después, le dice:
-Vos tenés que decirme cómo te hiciste rica -le dice.

(Muy despacio; como pensandolbien lo que está diciendo)

- Ah, es que yo -dice- yo le pedí-dice- a la...una varita una varita que me dieratta virtú; pero yo me fui por el río - dice- a lavar las tripas...cuando mataron el chancho. $Y$ æntonces esas tripas se me las llevaba la sardina, y yo le decía:

-Sardinita, dame mi tripita dice-. Sardinita, dame mi tripita; hasta que la ssardina me dio mi tripita, y con eso fue que yo -dice-me pude comprar los zapatos.

$Y$ entonces, dice:

-Ah, pues vamos a matar un chancho nosotrah para...para que también - dice- a ver; la cosa es que vos no te podés casar con un príncipe...

$Y$ matan un chancho y se...y se va la muchacha a lavar las tripas. Entonces, le dice:

-Sardinota, dame mi tripota.

Y se la llevó. Cuando se dio cuenta, se la habían tragado toda.

Y hasta ahí llegó. Colorín, colorado.

\subsubsection{María Cenicienta (3)}

(Narrado por Raimunda Gutiérrez Gutiérrez.

El cuento que voy a contar es el cuento de "María Cenicienta".

Había una vez, en un país lejano, un señor tenía una hija llamada María. Y resulta que... quedó m...este...huérfana de madre. Dispuso el papá casarse otra vez; pero la...la esposa que...que tuvo, que volvió a tener, tenía dos hijas. Entonce María...de'se tiempo atrá...adelante, ella recibió sólo malos tratos de la madrasta...y la maltrataban mal.

Resulta quel papá al tiempo murió...Quedó sola María. Ence la madrasta más la maltrataba y no la dejaban salir a ninguna parte, y la puso a dormir en la ceniza. Ella allí era onde dormía todo el tiempo. Y María para acá y que las hijas también la maltrataban, y la...y la que le pusieran los zapatos y que les...les trajera los vestidos y que, bueno, todo la ponían hacer en la casa y no la dejaban salir a ninguna parte. Ellas salían bien en carrozas al baile, a todo, y no la llevaban.

Al mucho tiempo de...de...de tener así a María, ella le puso María Cenicienta, verdá. Le dice:

- Vaya, María Cenicienta, a lavarme esas tripas al río - le díce - con el cuidao de que no se le vaya ninguna en el río; porque si usté me viene sin esas tripas, la castigo -le dice-. 
$\mathrm{Y}$ entonce, las tripas eran para hacer morcilla. $\mathrm{Y}$, bueno, se jue la María Cenicienta a lavar las tripas al río. Y se le van iyendo todas las tripas al río, veá, y se quedó sin ninguna tripa. Se sentó a llorar María Cenicienta en el río... En eso, se le aparece un viejito y le dice que

- ¿De qué llora, buen niña? -le dice-.

(Imitando la voz entre sollozos)

-Es que se me jueron las tripas en el río -dice- y ahora mi madrasta me va a pegar - dice-.

-No llore -le dice-. Vaya, cruce el río-dicey allá hay una... una ranchita ahí -dice-. Usté va -dice- hay una lora, hay unoh perroh -dicey...y usté se, se va y les mete palo a los perros -dice-, le pega a la lora y se su...se...se caga adentro -le dice-.

-Bueno-le dice- (Con voz humilde).

Y ya se jue María Cenicienta. Llegó, se puso a barrer la casa; se puso a moler maíz pa echarle tortilla a los perros y le dio masa a la lora. Ya cuando hizo todo eso, se volvió y ya encontró al viejito en el río.

- ¿Hizo lo que le dije?

-Sí señor -le dice- (Con voz humilde).

- Bueno, le vamoh a regalar este lucero que bie..., que le va a quedar bien lindo en la frente -le dice-.

Y era un gran lucero bien lindo que le había puesto. Bueno, ella se jue.

-Váyase, pueh.

Pero cuando Ilegó la...la madrasta...la...la regañó, nada mah; no le pegó.

Bueno, y las, y las otras muchachas se quedaron almiradas de verle el lucero que llevaba en la frente. $Y$ dice:

-Ay, ¿cómo te...que a...quién te regaló eso? -le dice una de'ella.

-Ah, un viejito que se me apareció en el río -le dice-. Pero yo tuve quir -dice-a la...me mandó a la casa dél - dice-para que le pegara a los perros - dice-, que me cagara dentro y le pegara a la lora - dice- - .

-Ay, -dice- imami, mami! (Ilamando) -dice- yo mañana voy a ir - dice- pa que me regale ese lucero - dice- ese viejito.

- Bueno, -le dice- mañana te vah voh -le dice-.

Ya se jue. Ese otro día se jue la... la hija de'lla; y ya hizo que se... se le iban las tripas al río, y las echó del río y se le jueron. Bueno, y ya se puso hacer que lloraba. y lloraba, y ai, en eso, llega el viejito y dice:

- ¿Qué le pasa, buen niña?
(Llorando):

-Es que se me jueron las tripas en el río - dice- y ahora mi mamá me va pegar - dice-.

-No Ilore -le dice-. Vaya allá -le dice- aquel ranchito - dice-; se caga adentro; le da palo a los perros y le da...le pega a la lora -le dice-.

-Bueno-dice-

En eso, ya, bueno, ya volvió. Dice:

- ¿Ya hizo lo que le dije?

-Sí, -dice la muchacha.

-Entonce, bueno - dice- le vamos a usté, le vamos a regalar esta gran faja de burro, veá, la gran faja. iJi, ji, ji!

$Y$ entonce (aún con risa)... y entonce, bueno, ya se quedó así.

Allá, un día, dicieron...dice la madrasta:

- Vamos ir al baile, muchachah.

-Bueno-le dicen.

-Bueno; se alistan temprano y noh vamos.

Se alistaron todas y alistaron la carroza. Se jueron pal baile. Se queda María Cenicienta Ilorando... y va de llorar y llorar, porque no se la llevaron. $Y$ entonce se le apareció un hada y le dice:

- ¿De qué llorah? , niña -le dice-

(Con voz sollozante):

-Es que mi madrasta no me llevó al baile - dice-. Todas salen y a mí no me llevan a ninguna parte - dice-y no me quisieron llevar.

-Bueno, ni llore -le dice-; tome esta varita mágica y usté le pide ahora el vestío más lindo -dice- y la carroza más linda - dice-. Todo lo que usté quiera: zapatos y todo -le dice-y usté se va pal baile. Pero, eso sí -le dice-a las doce en punto, usté tiene que estar en la casa.

- Bueno - dice- (Con voz humilde).

Ya se jue. Bueno, hizo lo que le dijo la hada y se alistó y se jue pal baile. Allá llegó él y bueno, le...la gente vio entrar la gran princesa que llegaba ahí; todos aplaudiéndola y de todo $y$, en eso, el príncipe a saludando y llegó y la saludó y:

- Vamos a bailar.

-Bueno, la...

Jueron de bailar y bailar (rápido) con el príncipe y, bueno.

Cuando allá... cuando ella vio que ya iban a ser las doce, le preguntó, le dice:

- ¿Quihoras tiene? -le dice-

-Son las doce -le dice-

- Ay, me voy - dice- porque yo quedé de ir.. salir... de llegar a las doce.

Y se jue María Cenicienta pa la casa; y jue tanta la carrera que... que hasta dejó el zapato perdido. Bueno, llegó a la casa y se metió a la ceniza. Cuan- 
do ya llegó la madrasta con las hijas, ya ella estaba en la ceniza. $Y$ ya entonce se acostaron sin echar de ver nada.

El rey... encontró la zapatilla ond'ella...onde la... la siguió... encontró la zapatilla.

- Bueno - dice- mañana - dice- a temprana hora - dice- voy a ir de casa en casa - dice- viendo de quién es este zapato - dice- porque la que sea la dueña d'este zapato - dice- me caso con ella.

Así se jue de casa en casa... probando el zapato, hasta que llegó a la casa onde estaba María Cenicienta. Entonce llegó y:

- Mire, buenos días.

- Buenos días, -dice- señor rey -le dice-

-Mire, que yo vengo a medirle los zapatos - dice- a sus hijas - dice-para ver cuál d'ellas jue que dejó anoche en el... regado este zapato - dice-. Es que la que sea la dueña-dice- yo me caso con ella.

-Ay, vení julana, vení zutana, vení a medirte el zapato - dice-

$Y$ ya ellas haciendo juerza ahi, pa meterse el zapato, a ver a cuál le quedaba...y a ninguna e las dos le quedó.

Le dice:

- Bueno, a ninguna le quedó - dice- ¿No tiene algún otra por ahí que tenga?

-No - dice- sólo esa - dice- que está ahí, en la ceniza -dice-. iQué va ser eso!, si ésa no sale a ninguna parte - dice- sólo vive metida en la ceniza -dice-; ésa no sale - dice-.

-Pero tráigala -le dice- para probárselo; con probar no... no se quita nada -le dice-.

Y ya vino y le probó el zapato... y le va quedando. Ella era la dueña 'el zapato.

- Pues me caso con ella - dijo el rey-veá.

$Y$ así jue. Bueno, y ya prepararon alistos para... para el matrimonio. El día que estaba...qu'era el día 'el matrimonio, vino la señora y alistó a una e las hijas, veá, las alistó para que se casara co el rey. El rey pues ni se fijó él... Salió con ella. Llegó él por ella y la montó en la carroza. Y ya iban con ella, cuando allá, por media plaza, le... una lora decía, este:

(Gritando)

- Lucero en frente quedó en casa -dice-; la

Faja de Burro va por la plaza -decía-.

Y ella gritaba duro:

- Lucero en frente quedó en casa -dice-; va...Faja de Burro va por la plaza - decía-.

Bueno.
-Oiga - dice- lo que dice esa lora. Vamos para atrás - dice -el rey-. Esto eh algo; vamos a ver quién jue la que quedó en la casa -dice.

$Y$ entonce dice:

- No, no - dice la señora- este, allá... allá nadie quedó.

-No, no; vamos para atrás -le dice el... el reyalgo dice esa lora - dice- vamos pa la casa otra vez.

Y van encontrando a María Cenicienta en la ceniza.

- ¿Ve? -le dice- aquí está -le dice- la que tiene el lucero en la frente -le dice-. Ella es -le dice-.

$\mathrm{Y}$ entonce, le dice:

-Así es que vamos alistar a María Cenicienta; porqu'ella es la que se va a casar conmigo.

$Y$ así jue que l'alistaron y todo, y se jueron para el matrimonio; se casaron y vivieron fiestas y de todo y... y María Cenicienta quedó feliz y... y ellas, las muchachas, quedaron viviendo ahí siempre, como... como estaban, por envidiosas.

Y colorín colorao. Este cuento si'acabao.

\subsubsection{María cara'e yegua (4)}

\section{(Narrado por Noé Bustos Rodríguez).}

El cuento de María cara'e yegua: Era un rey que tenía una hija. Había quedado viudo... y a ella la había criao una señora..., que ella sólo "Nanita" le decía. Fue creciendo, fue creciendo, hasta que se hizo una señorita... y el rey, cada día se enamoraba más de ella.

Allá, un día..., le dice:

-Hija, he tenido un sueño; pero vieras qué sueño... $\tan$ hermoso - dice-...

Entonces, ella le preguntó... que có... que qué era lo que había soñao.

-Pueh, hija, es que no me hallo en valor de decírtelo-dice-.

-Pero dígamelo, papá, ¿qué es lo que soñó... $\tan$ hermoso, $\tan$ bonito?

-Mirá -le dice- lo que soñé es... que estaba frente al altar, casándome con una hermosísima princesa... y que esta hermosísima princesa... que iba ser mi esposa en ese momento, eras vos. Y que tenés que hacer que ser mi esposa, porque me voy a casar con vos...

Le dice ella:

-No, papá, eso no puede ser... ¿Cómo va crer -le dice-que yo -le dice- voy a ser su esposa, siendo su hija? 
- iNo, no, no! Pues sí tiene que ser -le dice-. iPalabra de rey!

Ella le conversó a la viejita; porque ella l'encontró llorando. Le dice:

- ¿Qué te pasa, hijita, qué te pasa?

-Ay, Nanita, mi papá -dice-dice que yo tengo que ser su esposa. $\mathrm{Y}$, ¿cómo podrá ser eso, cuando soy hija d'él?

- No, mijita, eso no puede ser.

-Pues sí -le dice- porque ya me dijo que ese'ra palabra de rey.

-Bueno -le dice...- está bien... decíle que sí; pero que te traiga, que necesitás un vestido...color monte... en el mes de mayo, cuando los montes están reverdecidoh y floreadoh... un par de zapatillas para ese vestío.

-Bueno..., papá, -le dice- necesito un vestido color monte... cuando los montes están reverdecidoh -le dice- en el mes de mayo, con sus floreh y un par de zapatillah...para ese vestido.

-Muy bien, hija.

Y como él tenía un genio, entonceslollamó... llegó y le dijo quél necesitaba ese vestido. bajo).

-Sí, mi sacarreal, (5) se lo traeré. (Dicho muy

Se lo trajo.

-Hija, -le dice- aquiestá.

Ella lo agarró, lo vio y lo voló por ahí... Llegó la viejita. Ella está en lágrima viva...

-Sí, Nanita, mire... ahí está el vehtido.

-Ah vaina. iBueno! Ahora dígale... que usté necesita un vestido -le dice- color mar... con todoh los dibujos de los seres vivientes que hay en el mar... y otro par de zapatillah...

Bueno...Papá, necesito un vestido color mar...con todos sus sereh ...vivienteh que hay en el mar -le dice- dibujados en el...vestido y otro par de zapatillas.

-Ta bien, hija, ta concedido.

Llamó otra vez al genio y le dice.

-Sí señor... aquí está.

- Hijita, aquiestá el vestido.

Llega la viejita...Otra vez está ella Ilorando.

-Sí, Nanita, mire el vestido.

- iBueno! Ahora dígale...que usté necesita otro vestido color cielo... con todos sus astros... y otro par de zapatillas -le dice-

Llamó al genio otra vez, y le dice:

-Necesito un vestido.

-Ta bien...

Se lo trajo.

- Hija, aquí está el vestido, y aquí están las zapatillas.

Le hace el mismo, el mismo recibimiento: lo vuela por allá y se pone a llorar. Llega la viejita.

- Hijita, ¿y el vestido?

-Ahí está, Nanita...

- iQué va! - dice- esto no, no... esto no es posible - dice-... Bueno... ahora dígale al rey (muy rápido) -porque esto es lo último que él le va a conceder- dígale al rey que usté necesita que traigan todas las behtias al corral, y que ahí duerman, en el corral, para escoger el suyo...

Bueno, ya le dije al rey...que quería le trajeran todas las bestiah al corral, y que ahí durmieran para escoger ella el... el que a ella le gustara.

-Está bien, hija, pero es la última oportunidá que te doy.

Después le dice la viejita, ya cuando se iban acostar... le dice:

- Mirá, recogé los vestidoh que te dio tu padre, ahora diúltimo, color monte, color mar, color cielo y los zapatos... Todo esto lo hacés una sola; y aquí está esta cuerda... A las 12 de la noche, te levantáh... con todo lo que tenés listo y esta cuerda en la mano. Entrás al corral, das treh vueltas en el corral, por dentro, y el caballo que te siga, ese es el que tenés que llevarte... No te llevés otro, porque sos perdida. Tenés que llevarte el que te siga... y, si no lo hacés, -le dice- tás perdida.

-Sí, Nanita... Ta bien.

A las 12 de la noche, se levantó... cogió ese... esa cuerda y lo que tenía listo... se fue al corral. Dio la primer vuelta, y ya se quedó viendo el caballo que la seguía... el más desmedrao.

- Ah caballito - dice-.

Dio la segunda vuelta. Lo mismo. La tercer vuel ta y lo mismo.

-Pero idiay, así tengo que hacerlo.

Ya lo agarró; lo sacó... se montó... y quien se va es María Cenizosa... Ese animal por andar volaba. Le fue amanecer lejos, lejos... Ya llegaron de madrugadita. Le dice:

- Bueno, aquí -le dice- apé. Usté va trabajar -le dice- en la casa del rey... Ahí pide trabajo... cualquier trabajo... o lo que le den... Ahí trabaje... pero, eso sí, ahora tome este puñal... y me mata -le dice el caballo- me mata...

- iNo, caballito! (Con tono tajante y rápido)... ¿cómo vas a crer que yo te voy a matar?

- iMáteme! (Insistente)... Porque si no, usté es perdida... es perdida - le dice- porque a usté l'encuentran en cualquier momento... y asíes que, imáteme!

Vino... lo mató... Ahhh, antes de matarlo, le dice: 
-Después que me mate -le dice- me pela la cara, y el cuero de la cara mía se lo pone usté... pa que no la conozcan.

Lo mató; peló la la cara y ipa!, se la puso ella... Bueno, toda toda chocha; toda sucia... ya le dijeron que... la reina, pues que sí, ella tenía tres hijah y un hijo varón... que sí... pero allá, en el gallinero... cuidando gallinas... veá...que no llegara ni ahí, a los alrededores del del palacio... Le llamaban la María Cenizosa, la María Gallinera, la María Cara e Caballo. Bueno... Allá, un día, hay una fiesta... y ya llegó una de ellas... aá, onde está ella... le dice:

-María!

- ¿Sí?

-Fijáte que hay una fiesta - dice-en el centro.

- ¿Ah sí?

- ¿No vah con nosotrah?

-Si me llevan...

-Ahhh (cantando) iqué sería de nosotros -le dice-que fuéramoh con vos?

-Bueno -le dice- yo no le estoy diciendo que me lleve...

Bueno, se fueron ellas... Allá, en la noche... le tocan la puerta: iToc, toc, toc! (Toca madera tres veces).

- ¿Quién? - dice ella-

-Yo-le dice el caballo-

- ¿Qué quiere?

- ¿Queréh ir al baile?

- iClaro que sí!

-Bueno... quitáte esa cara... te poneh el vestido que te compró tu papá... color monte... y las zapatillas... Te arreglás... para que... nos vayamos.

Ya se arregló, y ya... Allá le dice:

-Bueno, aquí -le dice- te ehpero... en cuanto den las 12 , te venís; porque si no te venís -le dice-sos perdida.

Ya entró y van viendo ya que era una princesa... completa y de dónde había salido, cuando esa cara no la habían visto... Se enamora del hijo del rey y se copa con ella.... Cuando le dan el tan... $\tan . .$. (suena las palmas).

- Ahí te quedás, yo me voy.

Y se larga... al caballo y allá... al gallinero...

Ese otro día llegan las hijas del rey.

- Vieras, María, una muchacha que llegó anoche al baile... Pero iqué muchacha y qué vestido! -le dice-que andaba! Y... iqué par de calzado que ni nosotros, que somos hijas del rey!

- Ahhh - le dice ella- esa era yo.

-Ahhh, ¿qué dieras -le dice-si fueras vos?

- Ah, bueno, idiay...
La siguiente noche, vuelve a llegar... y le vuelve a tocar las puertas: iToc, toc, toc! (Toca tres veces en madera)

- ¿Quién?

-Yo, el caballo.

- ¿Qué quiere?

- ¿Querés ir al baile?

-Si me lleva... -le dice-

-Ponéte el segundo vestido que te compró tu papá -le dice-color mar... con las zapatillas d'ese vestido.

Se fueron al mismo lugar.

-Ya sabés... a las doce, te venís... No te quedés, porque sos perdida.

Bueno, cuando dieron las... quien se va es María Cara e Caballo... Ese otro día... la misma conversación.

- María, vieras qué muchacha la que llegó anoche... es la misma... pero con otro vestido superlindo.

-Ahhh - dice- era yo.

-Ahhh, ¿qué dieras que fueras vos?

- Ah, bueno.

Ya la... el último baile. Llega la misma hora y le vuelve hacer el toque: itoc, toc, toc! (Toca tres veces madera).

- ¿Quién?

-Yo, el caballo.

- ¿Qué quiere?

- ¿Querés ir al baile?

-Si me llevas...

-Alistáte. Ponéte el tercer vestido que te compró tu papá, color cielo, y las zapatillas para ese vestido...

-Bueno -le dice-

- A las doce, te venís... si no, sos perdida.

Cuando le dan las doce, ella hace viaje, y aquel príncipe, a como pudo, se zafó un anillo y ichás! , lo metió ahí, en el dedo.

-Este anillo, algún día, tengo que verlo...

Tenía las iniciales dél y todo... Y se fue. Llegó... Ya amaneció... Ya llegaron otra vez las mismas...

Allá, se enferma el príncipe... Enfermo, enfermo y enfermo. Ya por último, no comŕa... Pero ni comida que le hacía la la reina, la mamá...

Se da cuenta ella de que el príncipe está enfermo... Entonce se va a la cocina... Ta la reina haciéndole unos pasteles... y le dice:

- Mi reina, iquiere que le ayude hacer unos dos pasteles?

- iNo, no, no! (Con voz de susto) iDios guarde! Si se da cuenta... el príncipe -le dice- es capaz de que se muera. iNo, no, no! -dice-. 
-Idiay, ¿usté le va decir?

-No - dice- yo no le voy a decir... Pero... Bueno, hacéme unos dos.

Ya vino. Hizo unos dos y, en una que se descui. dó la reina, se zafó el anillo y ita!, lo metió en medio de un pastel... Y lleva los pasteles la reina... al príncipe... y... parte el primero y ahí sale el anillo, y coge él el anillo.

- iMamá! -dice-

- ¿Sí?

- ¿Quién le ayudó a usté (enfatizando cada palabra) -le dice- hacer estos pasteles?

- iNo, hijo, nadie, nadie, nadie! Yo, yo lo hice...

- iNo, mamá, a usté alguien le ayudó.

- iQue no, hijo!

- iQue si! -le dice- iSí! Y dígale ya -le dice-porque si no, me voy a morir...

-Mirá, hijo,... la única que me ayudó y que me hizo doh -le dice- eh María Cenizosa -le diceCara e Caballo.

- iPueh tráiganmela! (Gritando) -le diceporque ésa va ser mi futura esposa.

-Pero, ¿cómo así?

-Pues sí... La noche del último baile -le diceyo le puse este anillo en un dedo, y mírelo onde está... Ahí venía en un pahtel.

Entonces se van y ya le dicen a ella. Entonce, ella se despega aquella cara e caballo y se puso uno de los vestidos, y ya vieron que... que en verdá... esa era.

Se casó con ella. Vivieron feliz... Y yo aquí, sentado en esta silla... iJa, ja, ja, ja!

\subsubsection{Primero a Dios; después a la sal, y después} a usted (6)

\section{Narrado por Marina Raffo Cárdenas).}

En un pueblo muy lejano, como en una montaña, había un señor hacendado... muy rico... Y como él tenía tanta plata, él dominaba la gente de ese lugar... Y tenía sus criados que le obececían. Era muy celoso con una única hija que tenía. Pero tanto eran los celos, que le preguntó un día:

- ¿A quién quieres tú más... en el mundo?

$Y$ le dijo ella: usté.

-A... Primero a Dios; después la sal, y después a

Y él se enojó mucho. Como el señor se puso tan enojado, le dijo: hacer.
Y le preguntó para oír... Y le repitió lo mismo la joven.

-Si... si me volvés a decir eso la tercera vez, te mando matar.

Entonces, le preguntó, y le contestó igual la niña. Y él... dijo... a los criados:

- Llévenmela a matar a una montaña, donde nunca pueda saber dónde está, ni ella, ni el resto, ni nadie.

$Y$ los criados se alistaron, se fueron y se la llevaron. $Y$ fue de caminar montañas y montañas $y$ montañas... Y donde vieron que ella no se podía volver, porque... ellos no querían matarla porque les daba lástima, y les dijo:

-Aquí te perderé; pero no te matamos.

Entonce la dejaron sola en el monte y se regresaron. Ya el señor quedó contento, pensando que la niña se había muerto. Y... ella siguió caminando en el bosque. Fue de caminar, y pasaron tiempos, inviernos y veranos, y ella se le terminó el vestido que llevaba puesto, la ropa que llevaba puesta... Ya se iba a quedar desnuda. Tanta fue su preocupación, que que tuvo la suerte de encontrarse un cuero de un animal, y ese animal se llamaba "Mirra". Como ella vio que era como de un mono, al ponérselo le quedó bien cubierto el cuerpo... Todo bien tapado. Y siguió andando.

En esos días, ya tanto caminar, parece que se había alejado... acercado a un pueblo, no muy cerca, pero bastante lejos. Dispusieron los de esa escuela... de esos colegios... ir hacer un paseo. Se fueron hacer el paseo, y dijeron:

-Vamos ir a la montaña tal...

Una montaña que ellos nombraban. Y cuando... caminaron y caminaron... Entonce ella estaba por ahí y oyó el ruido de, de hombres, de personas que venían, y dijo:

-Ay, ¿cómo voy hacer ahora con este gente que viene? Me van encontrar aquí.

Y se subió a un árbol, el que vio que tenía máh hojas para cubrirse ella... tapada allá arriba, en ese árbol. Como ella estaba bien arriba, y ya llegaron ahí y dijeron los alumnos todo:

-Ay, iqué fresco está esto aquí! ... Aquí podemos almorzar.

Entonces se sentaron todos al contorno de ese árbol, y destaparon los almuerzos. Y ella, por allá entre las ramas, veía esas comidas y se le hacía agua la boca de ver que ella recordaba esos tiempos, cuando ella vivía donde su padre.

Pero entonce dijo ella a cortar unas semillitas que tenía ese árbol, y le volaba a unos muchachos que le gustaban a ella. Leh tiraba una semillita... 
Despuéh le tiraba a otro. Despuéh le tiraba a otro... Y tantah eran las semillitas, que llamaban la atención a, a todoh.

-Diay, ¿por qué caen tanto estas semillitas? (Dicho muy rápidamente).

$Y$ vieron para arriba, así, arriba del árbol; y vieron la... la... la joven ahí; pero no creyeron que era una persona; si no que un animal.

- iAy -dicen- bajémolo, bajémolo!

$Y$ ella haciéndose muy difícil para bajarse... y con el deseo de bajarse... Prestó la... comodidad, y se bajó. Entonce, un muchacho de esos... por casualidad, el que más le gustó a ella (con una risita contenida) este, dijo:

-Yo me la voy a llevar para mi casa.

Y se regresaron del paseo, y la llevó y la metió en su casa; en una casita como... donde se meten... así como una perrera; así... de animales que tienen afuera. $Y$ y la consideraban por verla que tenía una figura muy rara... y nunca habían conocido ese animal. Bueno, entonces, ya el muchacho, cuando llegó, dice... a los padres:

-Tengo deseos - dice-de casarme... y entonce, para eso, para encontrar yo una novia o una... es..., una mujer que a mí me guste, voy hacer una fiesta.

$Y$ invitó a todo el pueblo de ahí, para que llegaran todas las muchachas de ese lugar... a la fiesta... $Y$ ella oyó decir que ya era la fiesta, y todos se alistaron y se fueron. $Y$, cuando ellos se fueron, la muchacha se salió de esa casita y se metió a la casa, y llegó al ropero, donde había ropa de escoger de toda clase; tal vez hasta la más vieja que se habían puesto ellas; y se compuso en el tocador y se puso bien linda; y se fue preguntando dónde era el baile... y llegó. Y el muchacho, en cuanto la vio entrar, ésa fue la que le gustó a él... y se puso a.... (tose) atenderla con miles cosas. Y ya sólo con ella bailaba.

Ya en seguida, se ofreció... irla a dejar a su casa, y ella le dijo:

- No, no, - dice- mis padres son muy bravoh. Yo me tengo que ir sola.

-No, no, -dice- qué va. Para... para... probar - dice- que usté tenga seguridá que yo me voy a casar con usté, le voy a dar este anillo.

Y le dio un anillo, y ella se lo llevó y, como pudo, se zafó que no la vieran. Cuando echaron de ver, no estaba. Todo el mundo se alarmó y dice a buscarla y no supo. Bueno, el muchacho, de ese pesar, ya se terminó la fiesta y se fueron... Estaban en sus casas ya, y amaneció enfermo él de pesar que no sabía dónde vivía la muchacha. Y ya los padres, muy preocupados, le dijeron:
-Y ahora, ¿qué te vamos hacer de alimento? No querés ni comer.

-Sí, tráigame un chocolate -dice-.

Entonce, una de las criadas se puso hacer el chocolate. Y la... muchacha esa, que decían ellos que se Ilamaba "La Mirra"... descuidado se fue $y$ en la taza l'echó el anillo quél le diò. Entonce le Ilevaron el chocolate... y cuando se lo tomó, vio el anillo en el fondo de la taza, y dice:

- iY! (Con voz de sobresalto) Ehte es el anillo que yo le a... anoche a... a la muchacha esa de la noche. iAy! , voy a llamar a todos loh criadoh a ver de dónde cogieron este anillo.

Ya los llamaron.

(Muy rápido):

-No, yo no sé; yo no sé.

-Yo hice el chocolate, pero yo no... sé pero...

Nadie sabía nada.

-Llámeme a... a la Mirra.

Entonces la Ilamaron y, cuando llegó ella... este... le dice:

- ¿Usté sabe de este anillo?

Entonce le dijo ella:

-Sí, sí. Yo le cuento la historia d'ese anillo...

Entonce ya le contó lo que le había pasado a ella, y cómo había hecho. Entonces dice:

- Bueno, pero nos vamos a casar. Entonce... este... a... voy a mandarle a traer a las mejores... este... no... modas... y... y vestidos.

$Y$ de todo lo que se usara, para que se arreglara bien ella. Ya le compraron de todo, y ella se puso lo más linda y dijo:

Sí, yo me caso con usté; pero usté tiene que convidar a julano de tal.

$Y$ ese "julano de tal" era el papá d'ella, que vivía en otra hacienda, y él era de los ricos de ese lugar.

Entonces, él le dijo:

-Sí, sí; yo le prometo eso.

Y lo mandó a convidar:

-El matrimonio es tal día.

Ya se hizo el matrimonio. Llegaron ahí toda la gente; ya se casaron y llegaron al banquete. Pero ella se había propuesto hacer un plato de los de comida del banquete que no llevara sal. Entonce, ya se sentó a la orilla del papá... Pero él no sabía que ella era su hija. Y cuando estaban todos comiendo y se servían de todo, y él cogió esa comida y no le gustó, porque está simple (7). Y le pregunta: (carraspea)

-Buen señor, ¿usté por qué no come d' este plato? 
-Ay - dice- es que... está simple, y a mí lah cosas simples no me gustan.

Entonces le dice ella... Me... se paró y le dice:

-Me va perdonar; pero usté es mi padre - dicey me va perdonar, y lo perdono yo también; porque usté me mandó a matar, porque dijo estas palabras; que yo primero amaba a Dios, después la sal y después a usté.

El papá se sorprendió muchísimo, y la abrazó y dijo:

- Stamos perdonados y ustedes serán felices.

Y se terminó... el banquete.

\section{NOTAS}

Nota 1. Obsérvense, en esta narración, las siguientes particularidades estilísticas:

A. Tratamiento pronominal

1. La madrastra trata de "vos" a María Ceniza.

2. En cambio, la señora del río emplea, para ella, el "usted".

3. María Ceniza trata de "vos" a la varita.

4. El príncipe utiliza el "usted" para dirigirse a la madrastra de María Ceniza.

5. La señora del río comienza tratando de "vos" a la hermanastra de María Ceniza; pero después usa el "usted".

B. Aspiración de s:

Doña Enriqueta emplea poco la "s" aspirada.

C. Recursos expresivos:

1. En general, doña Enriqueta narra despacio; pero, cuando llega a pasajes decisivos, aumenta la velocidad hasta llegar, incluso, a un ritmo rapidísimo; como en las palabras que le dirige María Ceniza a la varita.

2. Hay mucho uso del polisíndeton; preferentemente, con la conunción " $y$ ".

3. Son más abundantes los pasajes dialogados que los narrados.

Nota 2. En este cuento, pueden destacarse los siguientes rasgos:

A. Tratamiento pronominal:

1. La madre emplea el "voseo para dirigirse a María Cenicienta y sus hijas.

2. María Cenicienta usa "vos" y "tú" para dirigirse a la varita; al hacerlo, los mezcla, con lo que demuestra una fuerte inestabilidad pronominal.
3. Dios y la varita tratan de "usted" a María Cenicienta.

4. Las hermanastras, de "vos".

B. Aspiración de S:

Curiosamente, hay más aspiración de $\mathrm{S}$ en los pasajes dialogados que en los narrados.

C. Recursos expresivos:

1. Doña Juana Pastora logra muy eficaces cambios de voz para imitar a los personajes.

2. Su velocidad de narración es uniforme.

3. Los párrafos narrativos son más largos.

4. Casi no introduce el diálogo: los personajes comienzan a hablar directamente.

Nota 3. En el cuento "María Cenicienta" de Raimunda Gutiérrez, se notan las siguientes peculiaridades;

A. Tratamiento pronominal:

1. La madrastra trata de "usted" a María Cenicienta y de "vos" a la hija.

2. El viejito del río emplea "usted".

3. Las hermanastras usan el "voseo".

4. El hada utiliza, para dirigirse también a María Cenicienta, el "vos" y el "usted", pero sin producir inestabilidad pronominal, porque las formas verbales se corresponden bien con cada pronombre.

5. El rey recurre al tratamiento de "usted", cuando le habla a la madrastra de María Cenicienta.

\section{B. Aspiración de s:}

Son muy pocos los casos en que la s se aspira.

C. Recursos expresivos:

1. En este cuento, la introducción es mucho más larga que en los cuatro restantes.

2. Existe predominio de los párrafos narrados sobre los pasajes dialogados.

3. Doña Raimunda posee gran destreza para imitar llanto, sollozos y gritos de los personajes.

Nota 4. En este cuento, "María cara'e yegua", aparecen las siguientes características:

A. Tratamiento pronominal: 
1. El padre y la reina usan el "voseo" para dirigirse a la muchacha.

2. Ella utiliza el "usted" cuando se refiere a su padre.

3. La Nanita la trata de "vos" y de "usted"; pero no llega a la inestabilidad pronominal.

4. Ella trata de "usted" a la Nanita, al caballo y a la reina.

5. El caballo utiliza el "usted" y el "vos".

6. Las hijas del rey emplean el "voseo".

B. Aspiración de s:

Don Noé emplea muy poco la s aspirada.

C. Recursos expresivos:

1. La velocidad narrativa es uniforme.

2. El diálogo casi ni se introduce. Por el contexto, se deduce cuál es el personaje que habla.

3. El texto posee variedad de ideófonos.

Nota 5. "Sacarreal": Es la forma popular con que se conocen los términos "sacra real". De la antigua expresión "sacra real majestad".

Nota 6. Algunos rasgos característicos del cuento "Primero a Dios; después a la sal y después a usted":

A. Tratamiento pronominal:

1. En el tratamiento del padre a su hija, hay inestabilidad pronominal; pues él utiliza $y$ mezcla formas del tuteo con las del voseo.

2. Ella trata al padre de "usted".

3. El muchacho se dirige a ella con el "usted", y ella lo utiliza también para él.

4. Los padres tratan a su hijo de "vos".

\section{B. Aspiración de s:}

Este es el cuento en que casi no hay s aspiradas; quizás una o dos en todo el texto.
C. Recursos expresivos:

1. Hay predominio de la narración sobre el diálogo.

2. En este cuento, hay más presencia del paisaje que en los otros.

3. Doña Marina posee un estilo narrativo un poco más monótono: utiliza muy pocos cambios de voz; la velocidad casi no varía y falta fuerza en los pasajes decisivos.

4. Aparece más falta de concordancia entre el suje to y el verbo.

Nota 7: "Simple": Dícese de la comida con muy poca sal.

\section{BIBLIOGRAFIA}

Aarne, Anti y Thompson, Stith. 1961. The Types of the Folk-Tale; a Classification and Bibliography. Helsinki: Folklore Fellows Communications, 184.

Dorson, Richard M. 1972. Folklore and Folklife. An Introduction. Chichago: University of Chicago Press.

Pinon, Róger. 1965. El cuento folclórico. Buenos Aires: EUDEBA.

Thompson, Stith. 1955. Motif-Index of Folk-Literature. A Classification of Narrative Element in Folktales, Ballads, Myths, Fables, Mediaeval Romances, Exempla, Fabliaux. Jest-Books and Local Legends. En seis volúmenes. Bloomington; Indiana; Indiana University Press. 